\title{
Editorial
}

\section{Sensors Best Paper Award 2013}

\section{Vittorio M.N. Passaro ${ }^{1}$, W. Rudolf Seitz ${ }^{2}$, Assefa M. Melesse ${ }^{3}$, Alexander Star ${ }^{4}$ and Ophelia Han ${ }^{5}$}

1 Dipartimento di Ingegneria Elettrica e dell'Informazione, Politecnico di Bari,

Via Edoardo Orabona n. 4, 70125 Bari, Italy; E-Mail: passaro@deemail.poliba.it;

Tel.: +39-08059-63850; Fax: +39-08059-63410

2 Analytical Chemistry, Department of Chemistry, University of New Hampshire, Durham,

NH 03824, USA; E-Mail: wrs@cisunix.unh.edu; Tel.: +1-603-862-2408;

Fax: +1-603-862-4278

3 Department of Earth and Environment, ECS 339, Florida International University,

11200 SW 8th Street, Miami, FL 33199, USA; E-Mail: melessea@fiu.edu; Tel.: +1-305-348-6518;

Fax: +1-305-348-6137

4 Department of Chemistry, University of Pittsburgh, 219 Parkman Avenue, Pittsburgh, PA 15260, USA; E-Mail: astar@pitt.edu; Tel.: +1-412-624-6493; Fax: +1-412-624-4027

5 MDPI AG, Postfach, CH-4005 Basel, Switzerland and MDPI Branch Office, Beijing 101101, China; E-Mail: ophelia.han@mdpi.com; Tel./Fax: +86-10-8152-1170

Received: 30 January 2013 / Accepted: 31 January 2013 / Published: 5 February 2013

Since 2011, Sensors has instituted an annual award to recognize outstanding papers that are related to sensing technologies and applications and meet the aims, scope and high standards of this journal [1,2]. This year, nominations were made by the Section Editor-in-Chiefs of Sensors from among all the papers published in 2009. Reviews and full research articles were considered separately. We are pleased to announce that the following eight papers have won the Sensors Best Paper Award in 2013:

\section{Article Award:}

$1^{\text {st }}$ Prize

Sabine Achmann, Gunter Hagen, Jaroslaw Kita, Itamar M. Malkowsky, Christoph Kiener and Ralf Moos

Metal-Organic Frameworks for Sensing Applications in the Gas Phase

Sensors 2009, 9(3), 1574-1589; doi:10.3390/s90301574

Available online: http://www.mdpi.com/1424-8220/9/3/1574 
$2^{\text {nd }}$ Prize

Alimujiang Fulati, Syed M. Usman Ali, Muhammad Riaz, Gul Amin, Omer Nur and Magnus Willander

Miniaturized pH Sensors Based on Zinc Oxide Nanotubes/Nanorods

Sensors 2009, 9(11), 8911-8923; doi:10.3390/s91108911

Available online: http://www.mdpi.com/1424-8220/9/11/8911

$3^{\text {rd }}$ Prize

Filiberto Chiabrando, Roberto Chiabrando, Dario Piatti and Fulvio Rinaudo

Sensors for 3D Imaging: Metric Evaluation and Calibration of a CCD/CMOS Time-of-Flight Camera Sensors 2009, 9(12), 10080-10096; doi:10.3390/s91210080

Available online: http://www.mdpi.com/1424-8220/9/12/10080

$4^{\text {th }}$ Prize

Litao Liu, Xiongying Ye, Kang Wu, Rui Han, Zhaoying Zhou and Tianhong Cui

Humidity Sensitivity of Multi-Walled Carbon Nanotube Networks Deposited by Dielectrophoresis Sensors 2009, 9(3), 1714-1721; doi:10.3390/s90301714

Available online: http://www.mdpi.com/1424-8220/9/3/1714

$5^{\text {th }}$ Prize

\section{Andrea Lingua, Davide Marenchino and Francesco Nex}

Performance Analysis of the SIFT Operator for Automatic Feature Extraction and Matching in Photogrammetric Applications

Sensors 2009, 9(5), 3745-3766; doi:10.3390/s90503745

Available online: http://www.mdpi.com/1424-8220/9/5/3745

Review Award:

$1^{\text {st }}$ Prize

\section{Alphus D. Wilson and Manuela Baietto}

Applications and Advances in Electronic-Nose Technologies

Sensors 2009, 9(7), 5099-5148; doi:10.3390/s90705099

Available online: http://www.mdpi.com/1424-8220/9/7/5099

$2^{\text {nd }}$ Prize

\section{Chuji Wang and Peeyush Sahay}

Breath Analysis Using Laser Spectroscopic Techniques: Breath Biomarkers, Spectral Fingerprints, and Detection Limits

Sensors 2009, 9(10), 8230-8262; doi:10.3390/s91008230

Available online: http://www.mdpi.com/1424-8220/9/10/8230 
$3^{\text {rd }}$ Prize

\section{Tianyou Zhai, Xiaosheng Fang, Meiyong Liao, Xijin Xu, Haibo Zeng, Bando Yoshio and Dmitri Golberg}

A Comprehensive Review of One-Dimensional Metal-Oxide Nanostructure Photodetectors Sensors 2009, 9(8), 6504-6529; doi:10.3390/s90806504

Available online: http://www.mdpi.com/1424-8220/9/8/6504

The prize awarding committee merits the article "Metal-Organic Frameworks for Sensing Applications in the Gas Phase" as "involving a new type of material as the adsorbent in gas sensors". Both of the reviews "Applications and Advances in Electronic-Nose Technologies" and "Breath Analysis Using Laser Spectroscopic Techniques: Breath Biomarkers, Spectral Fingerprints, and Detection Limits" "....introduced and explained their subject very nicely, while giving thorough, useful coverage of the literature."

These eight exceptional papers are valuable contributions to Sensors and the sensing field. On behalf of the Prize Awarding Committee and the Editorial Board of Sensors, we would like to congratulate these eight teams for their excellent work. In recognition for their accomplishment, Drs. Sabine Achmann, Alimujiang Fulati, Dario Piatti, Xiongying Ye and Davide Marenchino will receive $1000 \mathrm{CHF}, 800 \mathrm{CHF}, 600 \mathrm{CHF}, 400 \mathrm{CHF}$ and $200 \mathrm{CHF}$, respectively, and the privilege of publishing an additional open access format paper of their choice free of charge in Sensors in 2013. Drs. Alphus D. Wilson, Chuji Wang, Tianyou Zhai and Xiaosheng Fang will be awarded the privilege of publishing an additional research paper free of charge in open access format in Sensors.

\section{Prize Awarding Committee}

Editor-in-Chief, Section 'Physical Sensors'

\section{Dr. Vittorio M.N. Passaro}

Dipartimento di Ingegneria Elettrica e dell'Informazione, Politecnico di Bari, Via Edoardo Orabona n. 4, 70125 Bari, Italy

Tel. +39-08059-63850; Fax: +39-08059-63410

Website: http://dee.poliba.it/photonicsgroup

E-Mail: passaro@deemail.poliba.it

Editor-in-Chief, Section 'Chemical Sensors'

\section{Prof. Dr. W. Rudolf Seitz}

Analytical Chemistry, Department of Chemistry, University of New Hampshire, Durham,

NH 03824, USA

Tel. +1-603-862-2408; Fax: +1-603-862-4278

Website: http://www.unh.edu/chemistry/faculty/seitz_w.html

E-Mail: wrs@cisunix.unh.edu 
Editor-in-Chief, Section 'Remote Sensors'

\section{Dr. Assefa M. Melesse}

Department of Environmental Studies, ECS 339, Florida International University,

11200 SW 8th Street, Miami, FL 33199, USA

Tel. +1-305-348-6518; Fax: +1-305-348-6137

Website: http://www.fiu.edu/ melessea/

E-Mail: assefa.melesse@fiu.edu

Editor-in-Chief, Section 'Biosensors'

\section{Dr. Alexander Star}

Department of Chemistry, University of Pittsburgh, 219 Parkman Avenue, Pittsburgh, PA 15260, USA Tel. +1-412-624-6493; Fax: +1-412-624-4027

Website: http://www.pitt.edu/ astar/

E-Mail: astar@pitt.edu

\section{Managing Editor}

\section{Dr. Ophelia Han}

MDPI Beijing Office, Suite 2011, Ruidu International Center, Cuijingbeili No 1, Tongzhou District, Beijing 101101, China

E-Mail: ophelia.han@mdpi.com

\section{Reference}

1. Han, O. Sensors best paper award 2011. Sensors 2011, 11, 1243-1245.

2. Han, O. Sensors best paper award 2012. Sensors 2012, 12, 1127-1129.

(C) 2013 by the authors; licensee MDPI, Basel, Switzerland. This article is an open access article distributed under the terms and conditions of the Creative Commons Attribution license (http://creativecommons.org/licenses/by/3.0/). 